\title{
EVOLUCIÓN Y ETAPAS DEL DESARROLLO TURÍSTICO EN LA PROVINCIA DE CÓRDOBA, ARGENTINA: ¿CUÁN LEJOS ESTÁ EL IDEAL DEL TURISMO SUSTENTABLE? ${ }^{1}$
}

\author{
B. Eugenia Perona \\ Efraín V. Molina \\ Universidad Empresarial Siglo 21. Argentina
}

\section{RESUMEN}

El artículo analiza la situación actual del turismo en la provincia de Córdoba, Argentina, tomando como marco de referencia distintos modelos de etapas de desarrollo. Primero, se argumenta que la fase de desarrollo actual afecta de manera significativa la evolución futura del sector, especialmente en lo que respecta a la posibilidad de alcanzar un turismo sustentable. Segundo, se demuestra que a pesar del sostenido crecimiento experimentado por la actividad turística en Córdoba durante la última década, ésta presenta numerosos signos compatibles con una fase extractiva de desarrollo.

Palabras clave: etapas de desarrollo, evolución del turismo, turismo sustentable, Córdoba-Argentina.

Recibido: 26 de mayo de 2004

Devuelto para su revisión: 7 de noviembre de 2014

Aceptado: 19 de enero de 2015

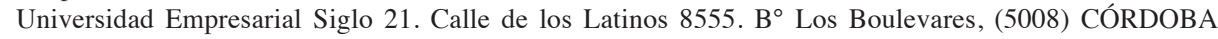
(Argentina).E-mail: eugenia.perona@gmail.com,efmolina@uesiglo21.edu.ar

1 Los autores agradecen a la Universidad Empresarial Siglo 21 por el apoyo académico y financiero brindado para la realización del trabajo, a Tamara Wasilcov por su colaboración con la recolección y procesamiento de la información, y a numerosos informantes que accedieron a ser entrevistados y proporcionaron valiosos datos para la investigación. Eugenia Perona también agradece a Panayiotis Tzanavaris por su estímulo y comentarios constructivos.

Dirección postal: Universidad Empresarial Siglo 21, Calle de los Latinos 8555, B ${ }^{\circ}$ Los Boulevares, (5008) Córdoba, Argentina.Email de contacto: eugenia.perona@gmail.com, efmolina@uesiglo21.edu.ar 
Evolution and stages of tourism development in the province of Cordoba, Argentina: How far is the sustainable tourism ideal?

\begin{abstract}
This paper analyzes the current situation of the tourism sector in the province of Cordoba, Argentina. Various models of development stages are used as a reference framework. First, it is argued that the current phase of development significantly affects the future evolution of the sector, especially regarding its ability to achieve sustainable tourism. Second, it is shown that, despite the sustained growth experienced by tourism activity in Cordoba during the last decade, there are numerous signs consistent with this activity still being in an extractive phase of development.
\end{abstract}

Keywords: development stages, tourism evolution, sustainable tourism, CordobaArgentina.

\title{
1. INTRODUCCIÓN
}

La idea de un turismo sustentable es abrazada en la actualidad como una nueva visión y un paradigma posible y deseable en el marco de un mundo globalizado (Harris, Griffin y Williams, 2002). Aunque el uso del término «sustentable» fue introducido en el ámbito del turismo recién en los años '90 (Buckley, 2012), la producción de literatura e investigaciones sobre el tema durante las dos últimas décadas ha sido notable.

En la práctica, no obstante, la sustentabilidad ha mostrado ser un concepto ambiguo. Si bien la noción de «turismo sustentable» se asocia en general con una preocupación por los impactos del sector sobre el ambiente, la comunidad y la cultura; ${ }^{2}$ algunos investigadores como Hunter (2002) han observado que muchos estudios carecen de pautas claras sobre lo que significa un turismo sustentable, lo cual hace necesario profundizar la elaboración teórica. A ello se suman problemas operativos y de medición, incluyendo la necesidad de diseñar indicadores apropiados (Cernat y Gourdon, 2012; Moscardo et al., 2013).

Desde una perspectiva aplicada, numerosos expertos coinciden en que la industria del turismo - especialmente en su versión tradicional o mainstream- está lejos de haber alcanzado estándares adecuados de sustentabilidad. La defensa de un turismo sustentable ha sido en gran medida retórica y en aquellos casos en que se han adoptado medidas concretas, muchas veces se ha actuado con un criterio pragmático u oportunista, dado que las mismas resultaban consistentes con mejoras en la imagen, las relaciones públicas o las metas empresariales de maximización del beneficio (Weaver, 2012; Buckley, 2012).

A pesar de las dificultades de orden teórico y práctico que se presentan, no son pocos los autores y organizaciones que mantienen una visión positiva sobre el futuro de la indus-

2 Véanse las definiciones adoptadas por la Organización Mundial del Turismo en su «Código Ético Mundial para el Turismo». En línea: http://ethics.unwto.org/es/content/codigo-etico-mundial-para-el-turismo (recuperado el 28/04/14). 
tria del turismo y su transición progresiva hacia prácticas que aseguren una mayor sustentabilidad. En un reporte de la UNESCO que analiza la relación entre cultura y turismo sustentable, Robinson y Picard afirman, por ejemplo, que «aunque el turismo global es un sector altamente complejo y fragmentado en su operatoria, el mismo ha cambiado significativamente sus actitudes... [y hoy] se muestra mucho más predispuesto a cooperar con la agenda del desarrollo sustentable...» (2006:12). En el mismo sentido, Griffin (2002) se proclama explícitamente optimista respecto de las perspectivas de un turismo sustentable y Weaver (2012) llega a plantear que el camino a la sustentabilidad es inevitable, surgiendo ésta como una etapa avanzada en el desarrollo del turismo a la que se puede arribar por medio de distintas trayectorias.

El presente trabajo aborda el caso del turismo en la provincia de Córdoba, Argentina, el cual se ha transformado en uno de los sectores más dinámicos de los últimos años. En sólo una década la actividad turística en Córdoba duplicó su volumen en términos reales, creciendo a una tasa del 6,4\% promedio anual (Perona et al., 2013). El número de visitantes que llegan a los distintos destinos de la provincia alcanzó casi 7 millones de personas en 2013, contando Córdoba en la actualidad, según fuentes oficiales (INDEC, 2012), con alrededor de 1,5 millones de plazas promedio disponibles por mes, entre establecimientos hoteleros $(61 \%)$ y para-hoteleros $(39 \%)$.

El crecimiento turístico de la región ha sido sin dudas destacado, contribuyendo a esta expansión el hecho de que Córdoba posee una de las ofertas turísticas más diversificadas de Argentina (incluyendo bellezas naturales, sitios históricos, organización de eventos, atractivos científicos y culturales, entre otras posibilidades); así como una capacidad potencial que supera ampliamente a la de otros destinos del país.

En este contexto y siendo que la actividad turística en Córdoba parece haberse expandido y consolidado como un sector importante, es oportuno preguntarse sobre la trayectoria escogida para su desarrollo. ¿Qué tipo de turismo es el que se está promoviendo? ¿Cuáles son sus impactos en términos económicos, sociales y ambientales? ¿En qué medida es el camino elegido compatible con las premisas del turismo sustentable, que tan enfáticamente son defendidas tanto en la literatura como en la prédica de las organizaciones internacionales?

Un examen preliminar de la situación del turismo en la provincia de Córdoba revela que, más allá de los datos exitosos sobre crecimiento del sector, el panorama en cuanto a sus impactos y posibilidades de desarrollo futuro, dista de ser claro. A simple vista pueden detectarse algunas dificultades que, aunque no han sido objeto de estudio sistemático, son ampliamente reconocidas y causan preocupación entre algunas comunidades, funcionarios y/o actores del sector. Entre otras cuestiones pueden mencionarse: el desarrollo no planeado y la congestión edilicia en algunas localidades, la contaminación de ríos y lagos, la precariedad de los empleos que genera el sector, y la volatilidad que caracteriza a una actividad sujeta a fuertes variaciones estacionales y dependiente en gran medida de las condiciones macroeconómicas y sociales del país.

El objetivo del presente trabajo es el de analizar la situación actual del turismo en Córdoba, desde el punto de vista de sus etapas de desarrollo. Una hipótesis central de la investigación es que, si bien en términos de volumen y crecimiento la actividad turística de esta provincia argentina es compatible con un turismo de masas, la misma exhibe, 
simultáneamente, numerosos indicios consistentes con una fase extractiva de desarrollo. En otras palabras, las prácticas generalizadas que se observan en el sector, no sólo están lejos de ser sustentables, sino que además no revelan un desempeño adecuado en términos empresariales. Esto sin dudas plantea una problemática diferente a la de otros destinos turísticos, tanto en Argentina como a nivel internacional.

En efecto, al debatir la necesidad y posibilidades de un turismo sustentable, gran parte de las contribuciones actuales hacen hincapié en la transición desde un desarrollo turístico masivo, basado predominantemente en una visión comercial y de negocios, hacia otro estilo de desarrollo (virtualmente superador) que toma en cuenta los impactos sistémicos del turismo, incluyendo sus consecuencias sociales y ambientales. Siendo así, ¿cómo se debería enfocar el problema en el caso de destinos que ni siquiera manifiestan signos avanzados de evolución empresarial? ¿En qué medida la evolución hacia una fase de mayor sustentabilidad se ve limitada por una situación de atraso organizacional y tecnológico y uso extractivo de los recursos? La respuesta a estas preguntas es relevante ya que podría arrojar luz sobre algunos de los dilemas que enfrentan, principalmente, los destinos turísticos de países en desarrollo (Ghimire, 2001; Harrison, 2001a; Weaver, 2002).

En las siguientes secciones se busca avanzar en la comprensión y caracterización del estadio evolutivo en el que se encuentra la industria turística cordobesa. Para ello se trabaja con un modelo conceptual de tres etapas, que busca adaptar, extender y hacer operativos desde un punto de vista empírico, diversos conceptos expuestos en la literatura sobre desarrollo turístico. Al mismo tiempo, se hace uso de algunas nociones propuestas en el campo de la economía evolucionista e institucional, las cuales contribuyen a dotar de unidad conceptual al análisis.

La realización del estudio se justifica por múltiples motivos. En primer lugar, Córdoba es una región turística de gran trascendencia en Argentina, que sin embargo no ha sido objeto de un análisis sistemático y fundamentado en la teoría. Los estudios disponibles consisten principalmente en informes técnicos (e.g. IIE, 2011; IERAL, 2011; Ricci, 2013; Tavella et al., 2010), donde se sistematizan algunos datos y se elaboran panoramas y tendencias, o bien indicadores parciales, sin abordar el tema desde un marco analítico más sofisticado o interpretativo de la realidad. En segundo lugar, la investigación sobre turismo en Córdoba revela falencias en cuanto a la información disponible, que muchas veces es inconsistente, incompleta, atrasada y/o limitada para comprender la problemática del sector. En tercer lugar, el fuerte crecimiento experimentado por la actividad turística provincial en los últimos años puede llevar a ocultar algunos aspectos perniciosos de la realidad del turismo local, promoviendo el status quo o el diseño de políticas y acciones que quizás no sean las más adecuadas. En este sentido, es necesario llamar la atención sobre el tipo de desarrollo turístico que se está gestando.

A continuación se presentan los antecedentes y el marco conceptual que servirá de guía para orientar el trabajo empírico posterior. En la Sección 3 se describe el caso de estudio, con el fin de ofrecer al lector un panorama más detallado sobre la naturaleza de la actividad turística en la provincia de Córdoba. En la Sección 4 se lleva a cabo el análisis, aplicándose el modelo de tres etapas al caso propuesto. La última sección recoge las conclusiones del trabajo. 


\section{MARCO TEÓRICO: MODELOS DE DESARROLLO TURÍSTICO}

El análisis de la evolución de fenómenos sociales a través de distintas fases de desarrollo, encuentra su fundamento en la literatura en economía evolucionista. Dicha corriente distingue entre diversos tipos de evolución, incluyendo una visión desarrollista y otra genética, que a su vez reconoce la existencia de procesos filogenéticos y ontogenéticos (Hodgson, 1993). En particular la ontogénesis se refiere al desarrollo de un organismo singular en el tiempo, desde su origen hasta su madurez y/o declinación, pudiendo a su vez entrañar una adaptación secuencial a los elementos del contexto (Hodgson, 2011). Los procesos ontogenéticos se aplican no sólo a individuos, sino también al estudio del crecimiento y transformación de entidades agregadas, como por ejemplo organizaciones o sectores socio-económicos (Lindemans, 2012). Partiendo de esta base, en las páginas siguientes se concibe al «sector turismo» en el área de destino de la provincia de Córdoba, como una estructura u organismo en sí mismo, cuyo desarrollo es pasible de ser clasificado y examinado a través de un conjunto de etapas.

La idea de observar la evolución del turismo a través de una secuencia de fases o etapas no es nueva. Un trabajo pionero y ampliamente citado en este campo es el de Butler (1980), cuya teoría del «ciclo de vida de los destinos turísticos» propone seis fases estilizadas de desarrollo, típicas del progreso de un área turística bajo un sistema de libre mercado: i) exploración, ii) inicio, iii) desarrollo, iv) consolidación y v) estancamiento. La etapa vi) se bifurca en varias opciones posibles: rejuvenecimiento, estancamiento continuado, o bien declive.

Desde su publicación, el aporte original de Butler ha dado lugar a numerosas extensiones, aplicaciones y debates teóricos y metodológicos (Ma, 2013; Butler, 2011). Algunos autores consideran a la teoría del ciclo de vida como una «... 'tipología ideal' de desarrollo del turismo, en base a la cual evaluar la evolución empírica de áreas de destino...» (Harrison, 2001b:4). Un ejemplo reciente de esto último es el artículo de Montaño Armendáriz et al. (2014), quienes aplican el modelo al caso de la localidad de Los Cabos en México.

La teoría de Butler también ha sido recogida en el marco de discusiones de carácter conceptual, debido a que, en principio, plantea una relación conflictiva entre la expansión del turismo y sus impactos sobre el ambiente. Para Weaver y Lawton (1999), el modelo de Butler expresa en forma sintética las críticas que un grupo de autores planteara durante los años '70 y ' 80 ante el avance del turismo de masas. Palmer-Tous et al. (2007), por el contrario, destacan el carácter pasivo de la teoría, afirmando que no permite tener en cuenta interacciones más complejas entre el turismo y el entorno en el que tiene lugar. Con una mirada retrospectiva, Butler mismo ha afirmado recientemente que «la razón para la longevidad [de la teoría] del ciclo de vida no es del todo clara» (2011:3). Sin dudas, su atractivo reside en que ofrece una descripción intuitiva y plausible, además de relativamente simple, del desarrollo de un área turística.

Entre los aportes posteriores a la literatura sobre etapas de desarrollo del turismo se destaca la contribución de Weaver $(2000,2012)$, que propone un modelo de «escenarios de desarrollo de los destinos turísticos». Dicho modelo, más amplio y estructurado que el del ciclo de vida, incluye a este último como un caso particular. Esencialmente, Weaver busca describir el desarrollo de los destinos turísticos desde una fase incipiente de turismo circunstancial, hasta una etapa avanzada caracterizada por un turismo de masas sustentable. Para ello plantea distintos escenarios y trayectorias posibles, haciendo uso de un diagrama 
bidimensional, que toma como ejes o variables la escala o intensidad del turismo por un lado, y el nivel de regulación conducente a la sustentabilidad, por otro (Figura 1). Cabe destacar que la noción de «turismo sustentable» adoptada por el autor es la de triple sustentabilidad (en inglés triple-bottom line) económica, ambiental y socio-cultural, la cual es compartida por la mayoría de los investigadores en la actualidad (Weaver, 2012:1030).

Aunque en trabajos anteriores el autor ha admitido la posibilidad de que existan distintos tipos de transición a lo largo de las fases de desarrollo de un destino turístico (Weaver y Lawton, 1999; Weaver, 2000), su visión a largo plazo del sector lo ha llevado a afirmar recientemente que el camino hacia un turismo de masas sustentable es «...el resultado inevitable y deseado para la mayor parte de los destinos» (Weaver, 2012:1030). Este estadio puede alcanzarse por medio de diversas trayectorias, clasificadas como orgánica, inducida, e incremental; y representadas en la Figura 1 por medio de las tres líneas negras sólidas. La trayectoria orgánica corresponde al modelo tradicional de crecimiento, donde un destino se consolida en una fase de turismo masivo no sustentable, para luego (con el objeto de evitar la declinación) introducir regulaciones y medidas que en última instancia promueven una mayor sustentabilidad. La trayectoria incremental, por el contrario, supone un nivel elevado de regulación desde el inicio, ya que la protección del ambiente y la cultura se considera prioritaria y sólo se permite expandir la escala en forma gradual. Por último, la trayectoria inducida es representativa de aquellos destinos en que el crecimiento intenta ser controlado y planificado, a fin de compensar una expansión progresiva en la escala, con medidas regulatorias que desalienten la ocurrencia de efectos no deseados en las esferas ecológica y socio-cultural.

Evidentemente, la propuesta de Weaver no está exenta de limitaciones. La afirmación de que las distintas trayectorias convergen inexorablemente hacia un estadio de turismo masivo sustentable, unido a la conclusión de que las prácticas pro-sustentabilidad serán adoptadas en mayor medida por resultar más efectivas en el manejo de los recursos; son cuando menos controvertidas. No todos los estudiosos del desarrollo del turismo

\section{Figura 1 \\ TRAYECTORIAS DE DESARROLLO DE LOS DESTINOS}

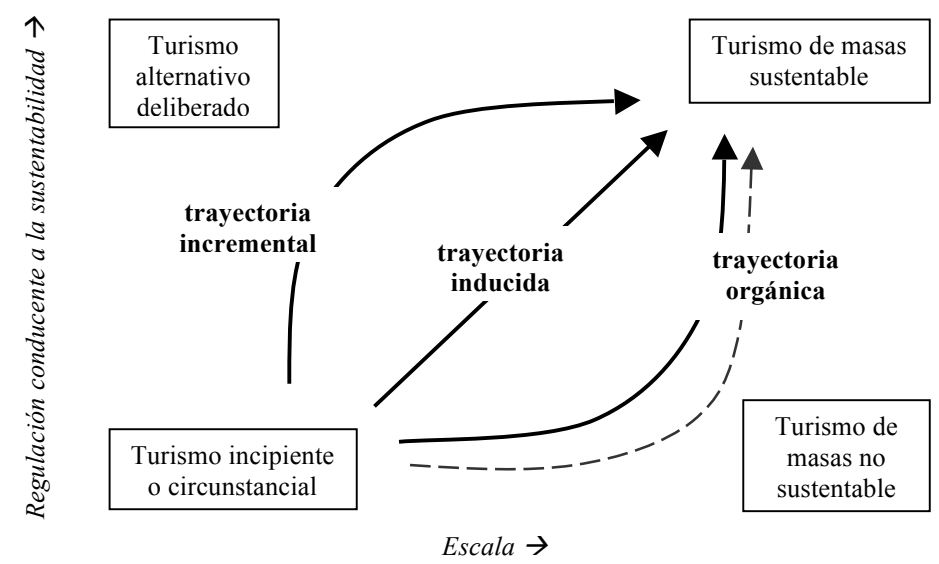

Fuente: Weaver (2012:1033), con modificaciones añadidas por los autores. 
comparten dicha visión optimista de la realidad y así lo han manifestado en sus críticas (Peeters, 2012). Sin embargo, aunque el modelo puede ser cuestionable como hipótesis de comportamiento, el mismo resulta útil como una herramienta heurística, ya que permite: i) visualizar las distintas fases de desarrollo de un destino, ii) reflexionar sobre los caminos posibles con vistas a lograr un turismo sustentable, y iii) ponderar los inconvenientes y desafíos que podrían presentarse en la transición de una etapa a la otra.

Una instancia de particular interés - dado que arroja luz sobre el caso del turismo en la provincia de Córdoba, que es el objetivo del presente artículo - es la posibilidad de transformación desde un turismo de masas no sustentable hacia uno sustentable, en el marco de una trayectoria de crecimiento orgánico (en la Figura 1, esto vendría dado por un tránsito desde el rectángulo inferior derecho hacia el superior derecho). Observando el modelo de Weaver, se advierte una limitación evidente y es que dicho modelo parece concebir al turismo de masas no sustentable como un estadio único y homogéneo. Tal generalización resulta problemática, ya que incluso en el caso de destinos caracterizados por un turismo de masas, pueden existir distintos estilos y niveles de desarrollo, lo cual a su vez incide de manera crucial en la potencial evolución hacia una fase de sustentabilidad.

En otras palabras, no es lo mismo un destino masivo que exhibe estándares avanzados en materia de organización, planificación, comercialización, tecnología, etc. - aún cuando puedan existir críticas respecto del manejo de variables ambientales o sociales - que otro destino, también masivo y cercano al límite de capacidad de carga, donde el turismo ostenta un patrón de crecimiento caótico y desorganizado, con escasa planificación y bajo uso de tecnologías. En términos de la Figura 1, se ha intentado describir esta última situación mediante la adición de una curva de color gris, en línea de puntos, por debajo de la correspondiente línea sólida que dibuja la trayectoria de crecimiento orgánico. El razonamiento es que un destino masivo «caótico» o «menos organizado», cuenta con un nivel incluso menor de regulación y andamiaje normativo (incluyendo normas formales e informales), respecto de un destino «eficiente» $\mathrm{u}$ «organizado». Consecuentemente, el primero se encuentra más alejado del objetivo de la sustentabilidad.

Esta distinción apunta de lleno a la brecha que existe en la expansión turística en países desarrollados vs. países en desarrollo, ya que es mucho más probable - aunque de ningún modo necesario - encontrar casos de destinos masivos con un escaso nivel de planificación y organización entre los segundos. Dicha probabilidad aumenta cuando el destino considerado se orienta principalmente al turismo doméstico, o cuando el turismo no es percibido como la principal fuente de sustento para la región. En estos casos, los incentivos para modernizarse o planificar el desarrollo son menores, lo cual no es un obstáculo para que, año tras año, los visitantes fluyan en gran número hacia esas zonas, acarreando beneficios sustanciales para quienes participan de la industria. Ghimire describe esta situación apropiadamente al afirmar que:

En casi todos los países en desarrollo, el avance del turismo doméstico generalmente tiene lugar sin ninguna planificación sistemática por parte del gobierno.... Cuando las inversiones del sector privado se hacen en esta actividad, las mismas son altamente sectorizadas, de corto plazo y motivadas a menudo por la obtención rápida de beneficios (2001:2). 
El modelo de Weaver no sólo no distingue entre las distintas variantes de desarrollo del turismo masivo, sino que la explicación que brinda el autor acerca de la transición hacia una etapa de turismo sustentable, deja en claro que se está enfocando principalmente en los países desarrollados y presuponiendo ciertos estándares mínimos de información y organización. Así por ejemplo, al enumerar los factores que, en su opinión, estarían impulsando prácticas sustentables en el turismo de masas, Weaver (2012) menciona: el precio de los recursos renovables, la mayor conciencia social acerca del cambio climático, la experiencia de la última crisis financiera global, el avance y compromiso de organizaciones ambientalistas, y la difusión que se logra a través de la internet y las redes sociales. Claramente, dichos factores están más presentes y causan un mayor impacto entre los empresarios y turistas de las naciones más avanzadas.

¿Por qué ocurre esto? Una vez más, la economía evolucionista e institucional puede aportar elementos conceptuales que contribuyen a esclarecer el problema. ${ }^{3}$ Según dicha escuela, para que tenga lugar un cambio sustancial a nivel de las instituciones y organizaciones de un sector - como el que requiere la transformación de un turismo menos sustentable hacia uno más sustentable - es necesario que una masa crítica de actores tome decisiones y lleve a la práctica distintos comportamientos consistentes con dicho objetivo. Para que ello ocurra los agentes deben, a su vez, verse motivados para tomar tales decisiones, lo cual sucede cuando: i) el contexto es favorable al cambio, y ii) sus fines y expectativas se ven intrínsecamente modificados en el sentido deseado. Dicho de otra manera, los actores relevantes en el sector - esto es, personas u organizaciones públicas o privadas relacionadas con el turismo - sienten que quieren realizar un cambio y perciben que es oportuno hacerlo.

El contexto en el que los actores toman decisiones se ve determinado de manera fundamental por el estadio de desarrollo alcanzado por un destino turístico en un momento dado, el cual viene definido por ciertas características que hacen a las organizaciones del sector, las empresas y oficinas públicas, el marco legal y normativo, las prácticas formales e informales prevalecientes, el espíritu innovador de los industriales y funcionarios, etc. También forman parte del contexto otros elementos más amplios del entorno político, económico, social, natural y tecnológico. Tomados en conjunto, dichos determinantes del contexto inciden de manera directa sobre las decisiones de los actores, habilitando o restringiendo oportunidades y posibilidades; y de manera indirecta, contribuyendo a moldear los fines, expectativas y hábitos de los agentes individuales. Las acciones emprendidas por estos últimos conducen, a su vez, a transformar las prácticas y normas que caracterizan al sector, y así sucesivamente (Figura 2).

El proceso descrito más arriba es evidentemente dinámico e incluye un fuerte componente de path-dependence, lo cual implica que la fase o estadio de desarrollo del sector en un momento dado condiciona de manera crítica su evolución futura. Por este motivo se afirmó anteriormente que si el objetivo último es alcanzar un mayor grado de sustentabilidad en el desarrollo del turismo, no da igual partir de una situación inicial caracterizada por un turismo de masas con un mayor (o menor) nivel de planificación y organización.

3 La presente sección se basa en las ideas desarrolladas por autores que hacen hincapié en los fenómenos de cambio social y transformación institucional (Hodgson, 2004, 2007; Ostrom y Basurto, 2011). Existen otras vertientes dentro de la economía evolucionista que han sido invocadas en estudios sobre desarrollo del turismo, como por ejemplo la «Geografía Económica Evolucionista» (véase e.g., el trabajo de Ma, 2013). 


\section{Figura 2 \\ PROCESO DINÁMICO DE EVOLUCIÓN DEL SECTOR}

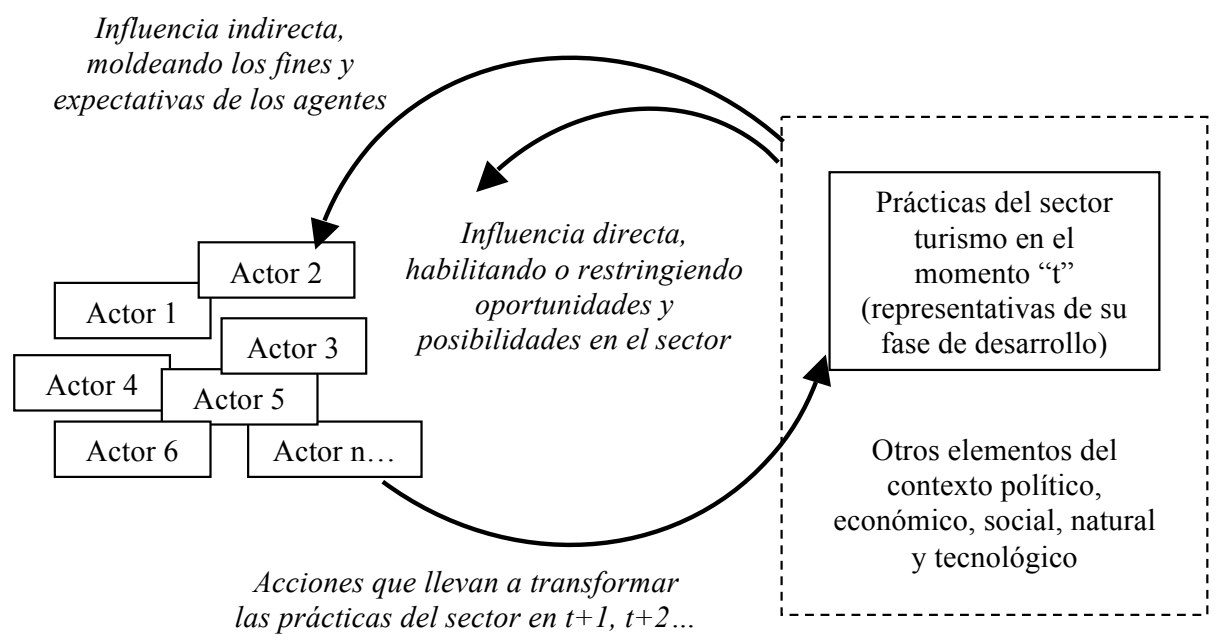

Fuente: elaboración propia en base a Hodgson (2004: Cap. 20).

Develar el modo específico en el que operan los distintos mecanismos de la Figura 2 es una cuestión empírica, que dependerá de la situación particular de cada destino o área turística. No obstante, es posible efectuar algunas consideraciones generales. En el caso de los destinos masivos «menos organizados» (o para ponerlo en la terminología de Weaver, con un menor nivel de regulación), caracterizados por la falta de planificación, conformismo y atraso tecnológico, entre otras cosas; el estímulo directo para llevar a cabo acciones compatibles con un mayor grado de sustentabilidad, resulta poco convincente. $\mathrm{Si}$ a esto se le suma un contexto político, económico y social en alguna medida adverso, la oportunidad para realizar dichas transformaciones se ve seriamente limitada. El contexto también influye de manera indirecta sobre las motivaciones intrínsecas de los agentes, que en el caso de estos destinos son menos proclives a defender objetivos de orden superior como la protección del ambiente y la cultura. Además, especialmente en los países en desarrollo, las personas están menos expuestas a los movimientos culturales y tendencias pro-ambientalistas que tienen lugar en los países desarrollados. Como expresa Griffin:

Es mucho más difícil ser optimista acerca de la posibilidad de que el turismo alcance la sustentabilidad en las naciones menos desarrolladas que en las desarrolladas. La necesidad de desarrollo económico es mucho más urgente, y los medios políticos y legales para controlar el turismo y sus impactos son mucho menos evidentes (2002:30).

La trayectoria de evolución hacia una fase potencial de turismo sustentable dependerá, en definitiva, de la interacción de las distintas fuerzas presentes en la determinación del contexto y la formación de fines. Una empresa o funcionario puede sentirse muy motivado para introducir cambios afines a un desarrollo sustentable, pero luego no contar con las condiciones adecuadas para poner en práctica su objetivo. Alternativamente, el gobierno 
podría promover medidas favorables a la sustentabilidad (mediante un enfoque de arriba hacia abajo o top-down), pero las mismas no encontrar eco en el sector privado en razón de que los actores no han internalizado esa meta como una necesidad propia. Finalmente, el modelo evolucionista ilustrado en la Figura 2 destaca la importancia de que exista una masa crítica de agentes predispuestos al cambio. Si las acciones transformadoras emanan sólo de las iniciativas de un grupo de individuos, organizaciones u oficinas públicas aisladas, con escasa capacidad de influencia y/o reproducción; lo más probable es que la situación general del sector se perpetúe en el tiempo y la transición hacia un estadio de mayor sustentabilidad (si es que ocurre), resulte más prolongada.

En síntesis, la fase o etapa de desarrollo que caracteriza a un destino turístico y que se revela a través de las prácticas, normas y reglas que guían el comportamiento de los distintos actores en el sector; no es neutral e incide de manera determinante sobre todas las fuerzas mencionadas arriba. El modelo de escenarios de Weaver no considera este hecho, ya que no repara en que la instancia de «turismo de masas no sustentable» - a partir de la cual, según el autor, surgen presiones para reconvertirse hacia un turismo sustentable - dista de ser un estadio homogéneo y puede presentar grandes variaciones de un destino al otro. En un trabajo anterior, Weaver reconoce el papel que cumple el contexto socio-político, económico, geográfico y cultural en el desarrollo del turismo, al sostener que «...las oportunidades y limitaciones inherentes a este medio externo influyen profundamente sobre la probabilidad de alcanzar un estado significativo de 'turismo sustentable'...» (2002:123). Lo que aquí se afirma es que no sólo es relevante tomar en cuenta el entorno o contexto general en el que se enmarca el sector, sino que es esencial prestar atención a la fase o etapa actual de desarrollo del sector en sí mismo.

\subsection{Un modelo de tres etapas}

Las consideraciones anteriores pueden emplearse como un marco general de referencia para analizar la situación del turismo en un destino particular, con respecto a su patrón de desarrollo. Sin embargo, antes de continuar avanzando es necesario plantear un modelo algo distinto, que permita operacionalizar las ideas vertidas arriba a fin de facilitar su aplicación empírica.

Partiendo del argumento de que el turismo de masas puede ser consistente con distintas fases o niveles de desarrollo, se debe establecer cómo distinguir entre dichos niveles ya que, en principio, es un concepto continuo que podría dar lugar a numerosas posibilidades. En lo que resta de la sección se propone una taxonomía o modelo de tres etapas que, aunque menos general desde un punto de vista teórico, resulta operativo en la práctica.

La diferencia entre esta taxonomía y el modelo del ciclo de vida de Butler o el de escenarios de desarrollo de Weaver, es que estos dos últimos toman como una variable crítica a la escala de explotación, distinguiendo entre un turismo menos masivo (ya sea porque el destino es incipiente o porque deliberadamente se lo mantiene como un sitio alternativo), y un turismo de masas. El modelo de tres etapas, por su parte, toma como variable fundamental al modo de utilización de los recursos - clasificándolo en un uso extractivo, productivo, o protectivo - con independencia de la escala. Tanto en un destino masivo como no masivo, pueden verificarse prácticas compatibles con las distintas formas 
de manejo de los recursos, considerándose que un uso extractivo (Etapa 1), es inferior o más atrasado a un uso productivo (Etapa 2), que a su vez es inferior o menos evolucionado que un uso protectivo (Etapa 3).

\section{Tabla 1}

\section{MODELO DE TRES ETAPAS Y SUS CARACTERÍSTICAS}

\begin{tabular}{|c|c|c|}
\hline Etapa & Características & Indicadores cualitativos \\
\hline Etapa 1 & $\begin{array}{l}\text { - Uso de los recursos: extractivo. Simple } \\
\text { explotación, se toma y se usa lo que está } \\
\text { disponible } \\
\text { - Ser humano: superioridad por medio de } \\
\text { la fuerza } \\
\text { - Noción de sustentabilidad: ninguna } \\
\text { - Áreas del conocimiento: ninguna, se em- } \\
\text { plean conceptos técnicos elementales y en } \\
\text { forma } a d-h o c\end{array}$ & $\begin{array}{l}\text { - Baja calidad de controles } \\
\text { - Comportamientos predato- } \\
\text { rios } \\
\text { - Escasa información y ele- } \\
\text { mentos de diagnóstico } \\
\text { - Acciones voluntaristas }\end{array}$ \\
\hline Etapa 2 & $\begin{array}{l}\text { - Uso de los recursos: productivo. Se apli- } \\
\text { can creatividad, ingenio y tecnología; se } \\
\text { «crean» nuevos recursos } \\
\text { - Ser humano: superioridad por medio de } \\
\text { la razón } \\
\text { - Noción de sustentabilidad: eficiencia } \\
\text { económica } \\
\text { - Áreas del conocimiento: Economía (en- } \\
\text { foque tradicional), Administración, Ges- } \\
\text { tión del Turismo }\end{array}$ & $\begin{array}{l}\text { - Emprendedorismo } \\
\text { - Capacidad de gestión y } \\
\text { planeamiento } \\
\text { - Uso de tecnologías } \\
\text { - Visión a largo plazo }\end{array}$ \\
\hline Etapa 3 & $\begin{array}{l}\text { - Uso de los recursos: protectivo. A la crea- } \\
\text { tividad y uso de tecnología, se añaden la } \\
\text { empatía y el cuidado } \\
\text { - Ser humano: superioridad por medio de } \\
\text { la sabiduría } \\
\text { - Noción de sustentabilidad: social, am- } \\
\text { biental y económica } \\
\text { - Áreas del conocimiento: Economía Eco- } \\
\text { lógica, Feminista, Evolucionista, Turismo } \\
\text { Sustentable }{ }^{(*)}\end{array}$ & $\begin{array}{l}\text { - Estudios de impacto am- } \\
\text { biental } \\
\text { - Polít. públicas y acciones } \\
\text { privadas protectivas } \\
\text { - Empleo de calidad } \\
\text { - Participación comunitaria }\end{array}$ \\
\hline
\end{tabular}

Nota: ${ }^{*}$ Incluye la nueva corriente denominada Hopeful Tourism (Pritchard et al., 2011).

Fuente: elaboración propia, adaptado de Perona (2014).

La Tabla 1 resume las principales características de cada etapa indicando, además del modo de uso de los recursos, el papel que se le atribuye al ser humano, la noción de sustentabilidad adoptada y las áreas del conocimiento relacionadas. Este último ítem se incluyó porque algunas revisiones sobre la disciplina del turismo, han centrado sus críticas 
en la visión economicista que impregna actualmente a la enseñanza y las publicaciones en la materia (Ren et al., 2010). Aún cuando sea válida, dicha crítica supone un sesgo hacia la investigación y las prácticas en los destinos más desarrollados. Aquellos destinos donde las prácticas son en gran medida extractivas, no crecen de acuerdo con los estándares difundidos en las escuelas de negocios, sino de manera más azarosa y hasta carente de fundamentos técnicos.

En la tercera columna de la tabla se han incluido algunos indicadores cualitativos que se emplearán más adelante en la aplicación empírica del modelo. Al respecto, es necesario aclarar que en un área de destino pueden coexistir distintas situaciones particulares en cuanto a la modalidad de uso de los recursos. Lo que aquí se intenta es realizar una evaluación global, respecto de las prácticas generalizadas y prevalecientes, a nivel del sector en su conjunto, con independencia de lo que ocurre en casos específicos o excepcionales.

Por otra parte, en las secciones siguientes se adopta un criterio prudencial, que implica que si se encuentra evidencia sustancial de que no se cumplen los requisitos necesarios para que un área de destino, de acuerdo con su fase de desarrollo, sea compatible con alguna de las etapas del modelo; ello es suficiente para asignarla a un estadio inferior. En otras palabras, el encontrar pruebas concretas, por ejemplo, de que las prácticas en el sector turismo son en gran medida no sustentables, basta para concluir que su desarrollo no puede ser calificado como correspondiente a la Etapa 3.

En lo que resta del trabajo, el modelo de tres etapas se utiliza para examinar la situación del turismo en la provincia de Córdoba. En particular, se busca demostrar que la actividad turística en dicha provincia argentina presenta numerosos rasgos consistentes con una fase o etapa extractiva de desarrollo, en concordancia con lo que más arriba se ha descrito como un turismo de masas menos regulado, o más atrasado en términos organizacionales.

Dicha conclusión es relevante porque, tal como se indica más abajo, no existe una conciencia generalizada de que esto sea así. La percepción que muchos funcionarios y empresarios tienen de la trayectoria de desarrollo del turismo en Córdoba, es considerablemente optimista y funcional al status quo. Asimismo, es posible conjeturar que la potencial transición hacia un turismo sustentable no será sencilla, dado que tanto los fines de los agentes como la realidad actual del sector, están poco alineados con dicho objetivo. Incluso entre aquellos actores públicos o privados que perciben la necesidad de una transformación o reorientación de ciertas prácticas, no se aprecia una preocupación marcada - más allá de un interés módico o circunstancial - por las metas de desarrollo social y/o protección del ambiente.

\section{EL CASO DE CÓRDOBA: DATOS Y PUESTA EN CONTEXTO}

Antes de continuar, en esta sección se presentan algunos datos sobre el turismo en Córdoba, que permiten contextualizar y poner en perspectiva el análisis sobre el desarrollo del sector.

La provincia de Córdoba está situada en el centro de Argentina. Las zonas sur y este son tierras fértiles, dedicadas principalmente a la agricultura para exportación, la ganadería y la industria. La zona del oeste es montañosa, con numerosos valles, ríos y lagos de particular belleza natural. Es principalmente en esta región (y en menor medida en el norte, 
más árido), donde se desarrolla la actividad turística. A ello hay que sumarle la Ciudad de Córdoba - capital provincial - que después de Buenos Aires constituye una de las dos urbes más grandes del país 4 .

Debido a que el presente estudio es de carácter macro o regional, es importante reiterar que a lo largo del trabajo se toma a la provincia de Córdoba como un «destino turístico» en forma integral, sin detallar las particularidades que hacen a cada una de las localidades y zonas del interior provincial. Dicho criterio se ve respaldado por el mapa de zonificación nacional establecido por el Ministerio de Turismo de la Nación, que considera a la provincia de Córdoba, en sí misma, como una «región turística» autocontenida.

Dos conceptos clave resumen las características de Córdoba como destino turístico: i) su diversidad y ii) su importancia dentro del turismo nacional.

Después de las playas de la costa atlántica en la Provincia de Buenos Aires, Córdoba es el segundo destino turístico de mayor trascendencia en Argentina. Este es un hecho poco conocido internacionalmente dado que Córdoba es principalmente un destino doméstico, con $96 \%$ de los visitantes de origen nacional, entre los cuales predominan las familias y los segmentos medios de ingreso (MINTUR, 2012). A nivel provincial, Córdoba es considerada por los residentes nacionales como el segundo destino ideal para el verano.

Otros destinos dentro de Argentina, como las Cataratas del Iguazú, el Parque Nacional Los Glaciares, los Caminos del Vino en Mendoza, o la Quebrada de Humahuaca; cuentan con una considerable exposición internacional. Sin embargo, por su volumen y capacidad, el movimiento turístico en Córdoba es mucho más intenso. Según datos oficiales (INDEC, 2012), Córdoba cuenta en la actualidad con alrededor de 1,5 millones de plazas disponibles por mes en promedio. Comparando por destinos, dicha cifra equivale a siete veces la cantidad promedio mensual de plazas disponibles en Iguazú, once veces la de Calafate, tres la de Mendoza y cuatro la de Salta. Si se toma el número de visitantes hospedados por año, Córdoba recibió en 2012 alrededor de cuatro veces más visitantes que Iguazú, Mendoza y Salta, respectivamente; y diez veces más que Calafate. Comparando por regiones, la provincia de Córdoba alcanza, por sí sola, un número de plazas y de visitantes similar a todo el Litoral, Cuyo, Norte, o Patagonia; siendo que cada una de estas regiones está integrada por cuatro a seis provincias y múltiples destinos turísticos.

El otro concepto clave que caracteriza a Córdoba como destino es su diversidad. La provincia se encuentra dividida en diez áreas turísticas, entre las que se destacan el Valle de Punilla, el Valle de Calamuchita y el Valle de Traslasierra; todos en la zona oeste del territorio. Estos tres valles explican el $70 \%$ del turismo provincial, participando con el $41 \%, 16 \%$ y $13 \%$ de la oferta de alojamiento, respectivamente (IIE, 2011).

También distingue a Córdoba la variedad de productos turísticos. Entre ellos, el turismo al aire libre ocupa un lugar prominente dado que la mayoría de los visitantes - especialmente en la estación de verano - busca disfrutar del aire puro, los ríos y la tranquilidad de los valles serranos. La geografía y los paisajes cordobeses son propicios para el turismo aventura, el turismo rural, el ecoturismo y el turismo de salud, con distintos grados de desarrollo según el caso.

4 Los siguientes sitios incluyen mapas, fotos y descripciones del destino turístico Córdoba: i) Secretaría de Turismo de la Nación, http://www.turismo.gov.ar/indexfs.html; ii) Agencia Córdoba Turismo, http://www. cordobaturismo.gov.ar/ (ambos recuperados el 28/04/14). 
La provincia ofrece cuantiosas oportunidades de turismo cultural, contando con sitios históricos relevantes como las Estancias Jesuíticas, a lo que se suman museos y sitios arqueológicos. Córdoba es sede de muchos de los festivales más importantes de Argentina, tanto en música - folklore, rock, tango - como en gastronomía. Esta última va de la mano de productos finos elaborados por descendientes de inmigrantes, así como por nuevos emprendedores. El turismo cultural comprende incluso posibilidades no convencionales como el «fenómeno OVNI» en la zona del Cerro Uritorco, donde numerosos visitantes se dan cita para celebrar eventos astronómicos y experimentar las cualidades energéticas del lugar.

Córdoba es, asimismo, una provincia amante del deporte y sede de diversos juegos y torneos. Posee una amplia oferta de circuitos de golf, un deporte que cobró auge a partir de algunos renombrados competidores oriundos de la zona. El trekking y el montañismo son actividades ideales para desarrollar en las sierras. También se destaca la organización de competencias automovilísticas (rally) que atraen a miles de turistas cada año, así como el turismo cinegético y la pesca deportiva.

Unido a los otros atractivos, no puede dejar de mencionarse el turismo académico en la Ciudad de Córdoba. La ciudad es sede de varias instituciones de estudios superiores entre las que sobresale la Universidad Nacional de Córdoba, que es la más antigua de Argentina y segunda en volumen de estudiantes después de la Universidad de Buenos Aires. Esta característica de Córdoba ha llevado a un fuerte desarrollo del turismo de eventos y conferencias, el cual ha crecido notablemente en la pasada década. También se ha incrementado el turismo estudiantil, idiomático y de posgrados, de la mano de una oferta de buena calidad y bajos costos en comparación con otros destinos. En adición a lo anterior, Córdoba es una provincia pujante, con un nivel importante de desarrollo industrial y agropecuario, por lo cual recibe numerosos visitantes en plan de negocios o de exposiciones y ferias que se realizan periódicamente.

Los párrafos anteriores permiten apreciar, en perspectiva, la potencialidad y diversidad que exhibe el sector turismo en Córdoba. Sturzenegger y Porto (2008) han estimado que por sus recursos turísticos, la provincia ocupa uno de los primeros lugares en el país, contando con $7 \%$ de los museos, $7 \%$ de los eventos científicos, $6 \%$ de los sitios naturales y $6 \%$ de los festivales de música folklórica, entre otras cosas. En el caso de algunos productos, como el turismo al aire libre en las sierras, el volumen de visitantes es claramente consistente con un turismo masivo. Otros productos ostentan un desarrollo aún modesto, pero que podría ser promisorio de mediar los estímulos adecuados.

Para cuantificar la magnitud y el impacto del sector turismo en la economía de Córdoba, es útil recurrir al cómputo del producto bruto de viajes y turismo (PBVT). Según este indicador, la actividad turística es actualmente la sexta más importante de la provincia, contribuyendo con alrededor de un 7\% del producto bruto regional (Perona et al., 2013). Con respecto al empleo, los datos de la Encuesta Permanente de Hogares (EPH) permiten afirmar que los puestos de trabajo en la industria de la hospitalidad (esto es, hoteles, bares y restaurantes), extrapolados al total de la provincia, ascienden a un 6\% del empleo de Córdoba.

La Figura 3 presenta dos índices relevantes, que ilustran el crecimiento sostenido que ha tenido la actividad turística en Córdoba. La línea más oscura describe el crecimiento del PBVT en términos reales en los últimos veinte años, pudiendo observarse que posteriormente a la fuerte crisis económica por la que atravesó Argentina en 2001/2002, éste se 
duplicó en volumen. La línea más clara muestra la evolución del número de visitantes por año (medido por la afluencia turística), que creció en forma sostenida, más que duplicando su magnitud entre 2002 y 2012. Se estima que en dicho año la provincia de Córdoba dio cuenta de un $12 \%$ del total de pernoctaciones en Argentina, tanto de residentes como de no residentes (MINTUR, 2012).

\section{Figura 3 \\ CÓRDOBA: CRECIMIENTO DEL TURISMO EN 1993-2012}

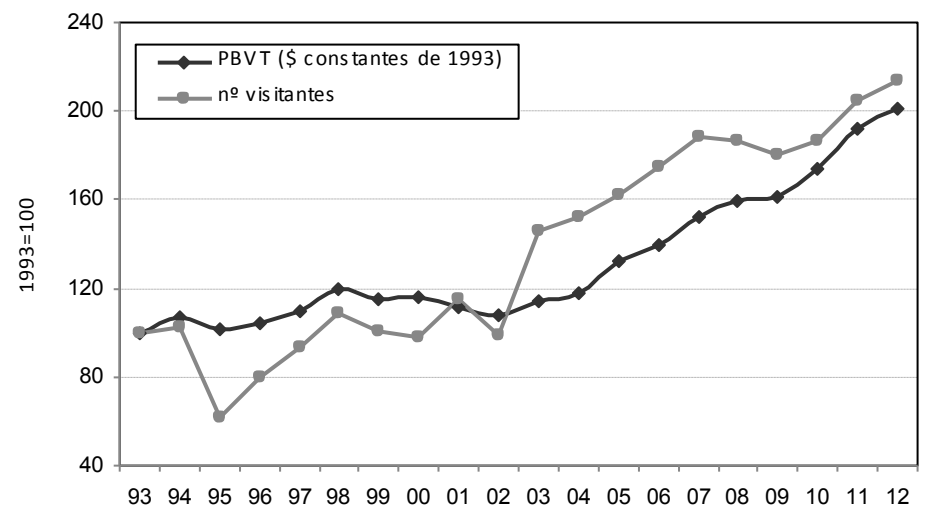

Fuente: elaboración propia en base a datos de la Dirección General de Estadísticas y Censos de la Provincia de Córdoba, IIE (2011) y MINTUR (2012).

El panorama descrito más arriba aparece, sin dudas, como relativamente auspicioso. Los comentarios y opiniones de funcionarios y empresarios del sector - que siguen con especial atención los datos de crecimiento, volumen y afluencia de visitantes - son particularmente optimistas. Y sin embargo, en este trabajo se afirma que dicho optimismo no está garantizado. El crecimiento y la potencialidad existen pero, mirando debajo de la superficie, las bases profundas sobre las que se asientan el patrón y trayectoria de desarrollo del turismo en Córdoba, generan suspicacias sobre la solidez y viabilidad a largo plazo del sector. En la siguiente sección se intenta demostrar el porqué de esta conjetura.

\section{APLICACIÓN DEL MODELO DE TRES ETAPAS}

Para analizar la fase o etapa de desarrollo que caracteriza actualmente a Córdoba como destino turístico, se emplean algunas de las nociones expuestas en el marco teórico. En términos del modelo de ciclo de vida de Butler, la sostenida expansión del turismo evidenciada en la provincia durante la última década - que de acuerdo con los pronósticos continuará produciéndose en los próximos años (IIE, 2011) - permiten ubicar a este destino como afín a las etapas de «desarrollo» y «consolidación», sin que existan señales aún de que haya alcanzado la fase de «estancamiento». Tal situación explicaría la actitud positiva de los agentes locales, cuyo entusiasmo refleja las proyecciones económicas para el futuro inmediato. 
Por otra parte, de acuerdo con el modelo de escenarios de Weaver, el turismo en Córdoba es compatible en gran medida, especialmente en el caso de sus productos típicos como el turismo al aire libre, con la etapa que el autor denomina como «turismo de masas no sustentable». Es indudable que muchos de los productos turísticos que Córdoba ofrece apuntan a un consumo masivo (no alternativo), y esto se ha logrado (y se sigue estimulando) mediante una expansión progresiva en la escala.

Ahora bien, según se afirmó anteriormente, dicho escenario de «turismo de masas» no es una categoría homogénea, pudiendo ser consistente con distintas modalidades en cuanto al uso de los recursos y grado de organización y regulación de la actividad turística. Estas características inciden de manera fundamental en la evolución potencial de un destino hacia un estadio de mayor sustentabilidad, ya que no es lo mismo partir de un turismo de masas con rasgos productivos e innovadores, que de uno poco organizado y con características extractivas.

La modalidad específica de desarrollo en términos de uso de los recursos puede ser revelada mediante la observación de las prácticas y normas que, de manera generalizada, guían el comportamiento de los distintos actores en el sector. Con este fin, en la sección 2.1. se propuso el modelo de tres etapas y se definieron algunos indicadores cualitativos correspondientes a cada una de ellas. A continuación, estos indicadores se aplican al caso de la provincia de Córdoba, evaluándose en primer lugar los criterios de sustentabilidad asociados con la Etapa 3 y posteriormente, los criterios de emprendedorismo propios de la Etapa 2.

Para llevar a cabo el trabajo empírico se emplean datos de diversas fuentes, incluyendo estadísticas elaboradas por organismos nacionales y provinciales, así como cálculos propios que sistematizan información que no se halla de otro modo disponible. Asimismo, se aportan diversos datos cualitativos, que fueron obtenidos mediante análisis documental, entrevistas a expertos y testimonios de profesionales relacionados con el sector. En cada caso se indica la fuente utilizada.

\section{1. ¿Es el desarrollo del turismo en Córdoba compatible con la Etapa 3?}

Esencialmente, lo que se intenta establecer en esta sección es que la actividad turística en Córdoba no es compatible con un uso protectivo de los recursos. Ello implica demostrar que no se cumplen los criterios para la triple sustentabilidad - social, ambiental y económica. De los tres aspectos, aquí se analizan sólo los dos primeros ya que son característicos de la Etapa 3, en tanto que la viabilidad económica es inherente a la Etapa 2.

Con respecto a la sustentabilidad social, Moscardo et al. consideran que «...se ha prestado una atención insuficiente a esta categoría y en consecuencia es mucho menos lo que se conoce acerca de los mecanismos que relacionan al turismo con sus impactos sociales» (2013:220). En dicho trabajo, los autores desarrollan algunos indicadores de sustentabilidad social, existiendo otras propuestas como la de Blancas Peral et al. (2010), que siguen los lineamientos de la OMT (2004).

En lo que sigue, el análisis se centra en un aspecto clave: la evolución del empleo. La misma puede ser considerada como un indicador mínimo de sustentabilidad social, ya que el crecimiento turístico debería, cuando menos, garantizar cierto impacto positivo en 
cuanto a la cantidad y calidad del empleo para la población local. Así lo entienden Cernat y Gourdon (2012:1048), que toman como criterios de sustentabilidad social: i) el número de puestos de trabajo creados por el sector, y ii) el salario medio en la industria del turismo en relación al resto de la economía.

En el caso de la provincia de Córdoba, los datos del empleo en el sector turismo durante la última década revelan un comportamiento sustancialmente distinto al del nivel de actividad. En tanto que el PBVT creció en forma sostenida entre 2003 y 2012 (véase la Figura 3 más arriba), el empleo no acompañó dicho crecimiento. El número de puestos de trabajo en la industria de la hospitalidad sufrió fluctuaciones considerables durante los últimos años y, aunque entre 2006 y 2011 creció en promedio un $15 \%$ con respecto a 2003, las cifras para 2012 no difieren de las de una década atrás. En síntesis, la fuerte expansión económica del sector no parece haberse traducido en más puestos de trabajo, especialmente en lo que hace al empleo formal, estable y con cierto nivel de calificación (Perona et al., 2013).

Una explicación posible para esta divergencia, está en la variación en el empleo no registrado, principalmente de carácter estacional, el cual presumiblemente ha crecido de manera significativa para acompañar la evolución de la actividad. Bajo tal categoría se incluyen, entre otros, trabajadores familiares, temporarios, ocasionales o de doble jornada; muchos de los cuales se desempeñan de manera informal.

No se dispone de datos específicos para cuantificar la magnitud del empleo no registrado en el sector turismo en Córdoba. ${ }^{5}$ Sin embargo, existen evidencias cualitativas de este fenómeno. En una entrevista realizada a fines de 2013, un funcionario de la Agencia de Promoción del Empleo de la provincia, experto en la problemática del sector, manifestó su preocupación por el alto nivel de informalidad en el empleo relacionado con el turismo. Según su testimonio, muchos trabajadores del sector son, por ejemplo, mujeres locales, que durante el verano deciden realizar una labor temporaria para obtener un ingreso extra para su familia. También hay trabajadores de otros sectores, que durante la temporada realizan una segunda actividad en forma complementaria. En otra entrevista en marzo de 2014, un profesional contable residente en La Falda - una ciudad turística de los valles serranos de Córdoba - se expresó en el mismo sentido, afirmando textualmente que se da una «elevada ocupación de recursos humanos, de manera informal y con niveles absolutamente disímiles en lo que respecta al precio pagado en concepto de sueldos».

Estos y otros testimonios y datos hallados, como el estudio cualitativo de Barrionuevo y Pan (2011) para la pequeña localidad de Cuesta Blanca, son reveladores de la volatilidad y precariedad que caracteriza al empleo en el sector. El empleo directo, formal y estable en la industria de la hospitalidad cordobesa no ha crecido significativamente en la última década, siendo éste un hecho que atenta contra el objetivo de sustentabilidad social.

Otro indicador relevante es la escasa participación comunitaria que se observa en la planificación del desarrollo turístico a nivel local. Por razones de espacio, no es posible desarrollar este aspecto en detalle, pero debe destacarse que es una situación típica de los países en desarrollo. Según Tosun (2000), existen limitaciones operativas, estructurales y culturales, que explican o dificultan la participación comunitaria en la

5 Se estima que, para el total de Argentina, el trabajo informal representa alrededor de un tercio del empleo. 
planificación turística dentro de las naciones menos avanzadas. Dichas limitaciones incluyen: i) escasez de información, experticia y capacidad de coordinación; ii) altos costos para la intervención comunitaria y falta de un sistema legal adecuado; iii) apatía y/o falta de conciencia y educación en la población. Muchas de estas dificultades se verifican en el caso del turismo en la provincia de Córdoba y han sido mencionadas por los expertos entrevistados, aunque sería necesario realizar una investigación específica sobre el particular.

Con respecto a la sustentabilidad ambiental, el progreso ha sido acotado y las medidas adoptadas son incipientes. A nivel nacional, existe una Red de Turismo Responsable (RTR) a la cual ha adherido la provincia de Córdoba, desarrollando a mediados de 2013 una serie de iniciativas conjuntamente con el sector privado. Las mismas apuntan a la adopción de medidas concretas, que sin requerir una gran inversión, contribuyen a reducir el impacto ambiental. Si bien el proyecto es reciente, es de esperar que algunas de estas acciones tengan éxito, dado que son consistentes con la visión «pragmática» de la sustentabilidad que ha sido documentada a nivel internacional.

Córdoba también cuenta con un Plan Estratégico de Turismo Sustentable (PETS, 2006), en cuya elaboración participaron actores y representantes del sector de las distintas regiones del interior cordobés. En el mismo se detectaron fortalezas, debilidades y oportunidades; proponiéndose una serie de acciones a mediano y largo plazo que incluyen, entre otras cosas, el problema de la estacionalidad, la mejora en la prestación de servicios, y la preservación del paisaje y los sitios históricos. El PETS representa una propuesta interesante, fruto de un esfuerzo consensuado. Sin embargo, hasta el momento, las acciones programadas están lejos de haberse implementado. Un funcionario provincial del sector confirmó recientemente este hecho, expresando que la incorporación de prácticas sustentables en el turismo provincial es limitada, lo cual se da, en sus palabras, porque «no hay una decisión de agenda a nivel gubernamental».

Otro desafío para la sustentabilidad ambiental es el reciclado y manejo de los residuos, que aparece como un aspecto crítico dentro de las consecuencias negativas derivadas del turismo de masas (Fortuny et al., 2008). La inadecuada gestión de los residuos sólidos en Córdoba es, de hecho, una de las mayores dificultades ambientales que enfrenta la provincia en la actualidad, estimándose que un 30\% de la disposición de los mismos se realiza en basurales a cielo abierto. ${ }^{6} \mathrm{Si}$ bien el problema afecta especialmente a los centros urbanos, la gran mayoría de los municipios y comunas se encuentra en una situación de vulnerabilidad.

También en este caso, la provincia cuenta con un instrumento formal denominado «Programa Córdoba Limpia», que depende de la Agencia Córdoba Ambiente. No obstante, en forma similar a lo que ocurre con el Plan de Turismo Sustentable, las acciones previstas no han podido concretarse aún. En algunas localidades turísticas del interior provincial existen iniciativas propias de reciclaje, como por ejemplo en Villa Giardino, pero no se aprecia una inquietud generalizada en este sentido.

6 Los datos fueron tomados del sitio oficial del Gobierno de la Provincia de Córdoba: http://www.cba.gov. ar/programa-cordoba-limpia/ (recuperado el 08/05/14). 
Un problema grave en términos ambientales y que afecta fuertemente al turismo, es el de los incendios en la zona de las sierras. Para combatir este flagelo, la provincia sancionó en 1999 la Ley de Manejo del Fuego, que establece el protocolo a seguir en caso de incendios y fomenta programas y acciones de prevención. Si bien esta herramienta ha servido como paliativo, no ha sido posible lograr una disminución en la incidencia del fenómeno. Tan sólo durante 2013 se quemaron alrededor de 100.000 hectáreas de bosque en los valles serranos, incluyendo la muerte de animales y la destrucción de residencias y alojamientos turísticos.

Por último y aunque no existen mediciones específicas, no se puede dejar de mencionar el problema del «desarrollo no planeado». De la mano de la gran expansión del turismo en los últimos años, el número de alojamientos en la provincia de Córdoba creció un 25\% entre 2005 y 2012 (MINTUR, 2006, 2012). En particular, es notable en dicho periodo el crecimiento de los hostel y albergues (144\%), hoteles sin categorizar (118\%), cabañas (79\%) y residenciales $(51 \%)$. Muchos de estos establecimientos operan de manera informal, atendidos por sus dueños y sin controles o habilitación. Cualitativamente, basta con observar el paisaje en muchas localidades serranas: donde hasta hace pocos años había campos y bosques, hoy hay construcciones y cabañas en alquiler, y algunos poblados fueron invadidos por comercios y edificios. Este fenómeno ha sido mencionado explícitamente en el PETS (2006:Cap.3) en relación a localidades del Valle de Punilla, Calamuchita y Traslasierra. ${ }^{7}$ La situación no llega todavía a un estado crítico, pero es urgente tomar conciencia de la misma, cuantificar su magnitud y adoptar medidas para proteger un recurso inherente al turismo como es el paisaje.

En suma, el crecimiento del turismo en la provincia de Córdoba no es, en su actual fase de desarrollo, compatible con las premisas de sustentabilidad social y ambiental, características de la Etapa 3. Los indicadores básicos que se han considerado en esta sección, sin pretender ser exhaustivos, no dejan dudas sobre dicha conclusión.

\section{2. ¿Es el desarrollo del turismo en Córdoba compatible con la Etapa 2?}

La Etapa 2 del modelo enfatiza el uso efectivo de los recursos y su puesta en valor, así como la «creación» de nuevos recursos a partir del ingenio humano y la aplicación de tecnologías. Tradicionalmente, los evolucionistas e institucionalistas se han referido a este proceso afirmando que las cosas «no son recursos, [sino que] se vuelven recursos» (De Gregori, 1987:1241).

Abrazar la Etapa 2 implica que la mayoría de los actores públicos y privados del sector turismo toman decisiones compatibles con las buenas prácticas empresariales y de gestión. Se utiliza el planeamiento estratégico, se tiene en cuenta no sólo el corto sino el largo plazo, se busca permanentemente generar nuevas ideas e introducir innovaciones, y se privilegian la planificación y la organización. El foco de esta etapa de desarrollo es la eficiencia económica. Por este motivo, muchos la consideran como un estadio inferior al de la Etapa 3, ya que no pone un énfasis explícito en los aspectos de sustentabilidad

7 Otros estudios recientes han reclamado por el avance de la frontera urbana en la zona de las Sierras Chicas. Véase la nota del 25/01/14 en: http://www.diaadia.com.ar/cordoba/sierras-chicas-no-debe-construir-mas (recup. el 08/05/14). 
social y ambiental. Por otra parte, la Etapa 2 resulta superadora cuando se la compara con niveles muy bajos de organización y gestión de la industria del turismo. En este caso, un aumento de la eficiencia, planificación y control es positivo, dado que podría redundar en un mejor aprovechamiento de los recursos.

En el caso de Córdoba, la visión mantenida en este trabajo es que el turismo provincial, tomado como un sector en su conjunto, no exhibe de manera generalizada un desarrollo consistente con la Etapa 2, ya que se observan deficiencias importantes en cuanto a los niveles de planificación, gestión y emprendedorismo. A continuación se presentan distintos aspectos e indicadores que avalan esta posición, agrupados en tres categorías: a) creatividad e innovación limitadas, b) planeamiento insuficiente, y c) falta de visión a largo plazo.

Con respecto a la creatividad e innovación limitadas, gran parte del crecimiento que se observa en el sector turismo en Córdoba en los últimos años ha estado basado en ideas y prácticas poco sofisticadas, que simplemente «aprovechan» la mayor afluencia de visitantes. Ya se mencionó la multiplicación de alojamientos básicos en las zonas serranas, que son construidos con una inversión mínima y con el objetivo de sacar réditos de la temporada. Por el contrario, el número de hoteles de alta calidad prácticamente no se ha modificado desde 2005, salvo un incremento en la categoría media de 3 estrellas y apart hotel (MINTUR, 2006, 2012). El florecimiento del comercio estacional, a pequeña escala e incluso informal, así como el cobro de tarifas a los turistas por el estacionamiento o el uso del espacio a la vera de los ríos (sin que exista en muchos casos una contraprestación que lo justifique); son otros ejemplos de una expansión económica basada en actividades simples y poco innovadoras.

El atraso tecnológico en los destinos turísticos es considerable. Muchas localidades del interior de Córdoba no cuentan con cajeros automáticos y, excepto en los comercios o ciudades más grandes, el uso de tarjetas de crédito es limitado. En numerosas ocasiones se observa que la tecnología llega con rezago y no se aprovecha su potencial. Esto es notable, por ejemplo, en el caso de las páginas de internet de las localidades turísticas. Un estudio propio, que incluyó veintinueve portales (públicos y privados) correspondientes a tres destinos destacados de la provincia, permitió determinar que los mismos son limitados en cuanto a su estructura y a la información que proporcionan al visitante, arrojando una puntuación promedio de 4 en una escala de 0 a $10 .{ }^{8}$

Otro indicio de una baja creatividad e innovación es la falta de aprovechamiento de oportunidades de negocios. Un caso concreto es la dificultad para acceder a los destinos del interior de Córdoba, desde la ciudad, en épocas de baja temporada. Durante el periodo laboral, la ciudad recibe numerosos visitantes con fines académicos, profesionales y de negocios. Muchos de ellos manifiestan interés por conocer las sierras u otros atractivos, pero la oferta de servicios no es adecuada. Un relevamiento realizado en 2012-2013 a ochenta agencias de viaje del casco céntrico de la Ciudad de Córdoba, mostró que sólo trece ofrecen excursiones en el día al interior provincial, subcontratando a un único proveedor. La mayoría de estas agencias requiere reservas anticipadas, un número mínimo de pasajeros y no ofrece rutinariamente guías en otros idiomas. En general, ninguna tiene presencia en los congresos científicos o eventos que se realizan en la ciudad. Si un visitante desea rea-

8 Los resultados de esta investigación serán publicados próximamente. 
lizar una excursión, debe movilizarse y/o buscar la información por sí mismo, lo cual obra como un desincentivo y reduce la posibilidad de utilizar los recursos más efectivamente.

El segundo aspecto a analizar es el planeamiento insuficiente. Si bien tanto el sector público como el sector privado comparten la responsabilidad por la planificación estratégica del turismo, es el estado - en todos sus niveles - quien cumple un papel fundamental en este sentido.

En el caso de Córdoba, el Plan Estratégico de Turismo Sustentable es un instrumento que da testimonio de los lineamientos trazados en materia de política turística para la provincia. Sin embargo, paradójicamente, la evaluación detallada que se hace de los distintos destinos del interior cordobés en el PETS (2006, véanse especialmente los capítulos 3 y 4), es altamente reveladora tanto de la ausencia como de la necesidad de planificación en el sector, en numerosos frentes. Para la mayoría de los destinos, son recurrentes las menciones y críticas a: i) la falta de un plan de desarrollo, ii) la incapacidad de coordinación entre el sector público y privado, iii) la escasa conciencia turística tanto de los pobladores como de las autoridades locales, iv) los problemas de infraestructura y equipamiento, v) la falta de inversión en recursos humanos y servicios esenciales, vi) la deficiente comunicación entre el gobierno provincial y los gobiernos municipales, vii) la carencia de regulaciones y control de los servicios turísticos, etc.

Algunos autores como Ghimire (2001) han sugerido que las dificultades en la planificación son frecuentes en el caso de destinos de países en desarrollo, especialmente cuando el crecimiento del sector está dominado por el turismo doméstico. Harrison (2001c) plantea que para los gobiernos de países en desarrollo es esencial definir el tipo de turista que se desea atraer, la inserción nacional e internacional, y la coordinación entre los distintos niveles de gobierno; todos aspectos que han sido señalados como problemáticos en el PETS de Córdoba. Asimismo, el autor advierte de que es relativamente sencillo formular planes para el turismo, «...pero no hay garantías de que una vez que... se presenta el informe, el plan será implementado con éxito» (ibid::38). Ello se debe, según Harrison, a la falta de voluntad política y de reconocimiento de los impactos sociales, a lo que se suma «...una retórica que no se ve equiparada por la acción del estado...» (ibid.:38). Efectivamente, esto es lo que acontece en la provincia de Córdoba y se pone de manifiesto reiteradamente en los datos, testimonios, documentos y observaciones del sector. Como se afirmó más arriba, el PETS es una herramienta positiva para la planificación, pero su instrumentación ha sido exigua.

El tercer aspecto, la falta de visión a largo plazo, está ligado a los anteriores. Un indicador que pone en evidencia esta situación, es la carencia de ideas y acciones destinadas a atemperar la fuerte estacionalidad que caracteriza al turismo en las zonas del interior de la provincia (Wasilcov y Perona, 2014). Dicho aspecto es crucial para el desarrollo de un empleo de calidad y un estímulo a las poblaciones locales, cuyos habitantes (especialmente los jóvenes) se ven en la actualidad forzados a emigrar a la ciudad en busca de trabajo, estudios y oportunidades.

Otra señal que delata una falta de visión de cara al futuro, ha sido la actitud remisa por parte de muchos actores del sector respecto de la exploración y expansión hacia nuevos productos, mercados y consumidores. A pesar de las grandes potencialidades que presenta Córdoba como destino, la apertura hacia nuevas formas de turismo se ha dado lentamente y ha debido superar diversas instancias de resistencia al cambio. 
Esto es preocupante ya que, en las condiciones actuales, es esencial buscar una mayor diversificación a largo plazo, con una oferta de calidad y una base de turistas más amplia que la existente. Hoy en día, la principal fuente de visitantes de la provincia está constituida por el turismo doméstico de verano y de fines de semana largos, más el público que visita la ciudad por razones laborales o familiares. Sin embargo, el turismo doméstico tiene un techo dado por el crecimiento demográfico, siendo además vulnerable a las fluctuaciones macroeconómicas del país. Sobre este punto, se ha comprobado que el turismo en Córdoba se comporta como un bien superior, con una elasticidad-ingreso mayor a 1 (Pussetto et al., 2013), por lo que el impacto de las crisis sobre el sector tiende a ser severo.

La escasa búsqueda de mercados alternativos lleva a reflexionar sobre la actitud y el papel que desempeña el sector privado. En una entrevista realizada en diciembre de 2013, un alto funcionario de la Cámara de Turismo de Córdoba se lamentaba por la poca inserción que tiene la provincia como destino en el ámbito internacional, teniendo en cuenta su potencial. Al ser consultado por la falta de interés que muestra el empresariado local por promover el destino puertas afuera, el entrevistado lo atribuyó principalmente al parroquialismo y falta de visión de algunos agentes locales, que parecen conformarse con el crecimiento experimentado en los últimos años por el turismo doméstico. En palabras textuales del funcionario: «La culpa es nuestra... Durante treinta años que nos convino el tipo de cambio nunca hubo un plan claro de promoción internacional». Dicha frase sintetiza, en gran medida, el estado de situación.

\section{3. ¿Es el desarrollo del turismo en Córdoba compatible con la Etapa 1?}

Resumiendo el argumento de las secciones anteriores, puede concluirse que el desarrollo actual del sector turismo en la provincia Córdoba no cumple con los criterios requeridos para ser consistente con un turismo sustentable (Etapa 3), pero tampoco alcanza el grado de avance necesario como para ser calificado como un turismo de características empresariales (Etapa 2). Esto último no niega que existan individuos, políticas, o emprendimientos particulares, con un espíritu innovador. Lo que se afirma es que el sector turismo, considerado en forma global o macro a nivel provincial, exhibe numerosos indicios de falta de planificación, organización, coordinación, emprendedorismo y uso de tecnologías.

Tomando como referencia el modelo de tres etapas, la actividad turística en Córdoba puede hoy describirse en gran medida como un turismo de masas de tipo extractivo, compatible con la Etapa 1. Muchos de los recursos que constituyen la base o fuente de los atractivos turísticos locales, simplemente se «toman» y se «usan», sin una verdadera puesta en valor, lo que da lugar a un sistema explotativo y de características predatorias. Dicha trayectoria de desarrollo no sólo no es triplemente sustentable, sino que tampoco es económicamente viable a largo plazo.

A esto hay que añadir el relativo desconocimiento que existe sobre numerosas variables del sector, debido a la escasez de datos y a la falta de sistematización y difusión de la información. En particular, se necesitan trabajos de campo y relevamientos de las zonas turísticas del interior provincial, que permitan generar indicadores de primera mano sobre aspectos como el empleo, la calidad del servicio, las condiciones ambientales o las preferencias de los visitantes. 
Dicho nivel de fragmentación en la información restringe fuertemente la posibilidad de elaborar diagnósticos y estudios en profundidad, así como de realizar un seguimiento continuo de la evolución del sector. Esto, a su vez, dificulta el diseño e implementación de políticas que conduzcan a un desarrollo del turismo en un sentido transformativo y positivo. Algunos empresarios y funcionarios públicos cordobeses se muestran genuinamente preocupados por la marcha del sector, pero al no poder respaldar sus inquietudes con datos y estudios rigurosos, dicha preocupación se traduce en declaraciones o acciones bien intencionadas, pero de tipo voluntarista, que no forman parte de un plan integral y coherente a largo plazo. ${ }^{9}$

En otras palabras, al uso extractivo que muchos actores hacen de los recursos turísticos, se superponen distintas iniciativas que operan como «parches» para intentar solucionar algunos de los problemas que afectan al sector. Si a ello se le suma la falta de coordinación presente entre los agentes públicos, privados, y a distintos niveles - la cual ha sido documentada elocuentemente en el PETS (2006) y otros informes (IIE, 2011) - el resultado es un desarrollo desordenado y con un fuerte componente idiosincrático.

Evidentemente, la conclusión de que el turismo en Córdoba se encuentra encuadrado en la Etapa 1 y está caracterizado por un patrón de desarrollo de tipo extractivo, puede no resultar aceptable para quienes observan (con ciertas expectativas) la expansión reciente de la actividad turística local, en términos de volumen de negocios y número de visitantes. Lo que aquí se intenta mostrar es que enfocarse en datos coyunturales sobre crecimiento - unido a la percepción optimista de que Córdoba es una región rica en posibilidades y recursos turísticos - no basta para comprender la naturaleza real y profunda del modo de desarrollo del sector.

\section{SÍNTESIS Y CONCLUSIONES}

El objetivo del presente trabajo ha sido el de analizar la situación actual del turismo en la provincia de Córdoba, desde el punto de vista de sus etapas de desarrollo. El análisis fue realizado teniendo presente, además, los desafíos y limitaciones que el sector turismo de esta provincia argentina necesita superar para orientarse en la dirección de una mayor sustentabilidad.

La primera conclusión del estudio es teórica. Elaborando en base a los modelos existentes sobre etapas de desarrollo del turismo se llegó a postular que el escenario o fase de «turismo masivo no sustentable» que alcanzan muchos destinos, no es una categoría homogénea, pudiendo exhibir distintas modalidades en cuanto al uso de los recursos y al grado de organización y regulación de la actividad turística. También se argumentó que el modo o etapa de desarrollo del sector turismo en un momento dado, condiciona de manera significativa su trayectoria futura, afectando, en particular, la naturaleza de la transición hacia un estadio más avanzado de sustentabilidad.

9 Por ejemplo, en el marco del Plan de Capacitación y Formación Profesional se entrena y otorga certificaciones a empleados de la industria del turismo, lo cual en principio es una acción positiva emprendida por el gobierno provincial (Agencia de Promoción del Empleo, 2013). Sin embargo, algunos de sus propios gestores manifestaron en una entrevista desconocer el verdadero nivel de empleo del sector, así como las características de la demanda ocupacional. 
En suma, se añade una nueva dimensión a los modelos tradicionales de etapas del desarrollo turístico, volviéndolos más complejos desde el punto de vista de su dinámica. Dicha complejidad se justifica no sólo por su mayor realismo, sino porque permite discutir la problemática específica de algunos destinos - típicamente de países en desarrollo - que presentan signos de un menor progreso en cuanto a sus niveles de planificación y gestión.

La segunda conclusión es empírica. Haciendo uso de los argumentos anteriores, se propuso y aplicó un modelo operativo de tres etapas al caso de la provincia de Córdoba. Tomando en cuenta distintos aspectos e indicadores, se comprobó que el sector turismo provincial está caracterizado por un patrón de desarrollo extractivo, consistente con la Etapa 1. A partir de esta constatación no es aventurado inferir que la transformación de las prácticas del sector hacia un turismo de naturaleza más sustentable, no será sencilla y demandará un tiempo considerable. En las condiciones presentes, tanto el contexto del sector como la visión de los agentes individuales, son poco favorables a la introducción de cambios fundamentales.

Dicho resultado no desmerece los esfuerzos de quienes proponen acciones renovadoras, ni tampoco desestima la gran potencialidad que posee la provincia en cuanto a sus recursos turísticos. El mismo advierte, sin embargo, sobre la necesidad de prestar atención a las condiciones estructurales de desarrollo del turismo, más allá de lo que se observa en la superficie. También pone de relieve la importancia de avanzar en el estudio y la comprensión de las distintas variables y mecanismos que hacen al funcionamiento de la actividad. El hecho de que Córdoba sea el segundo destino turístico de Argentina, vuelve a este exhorto aún más significativo.

Indudablemente, quedan muchas preguntas por responder. En el trabajo se ha privilegiado la elaboración taxonómica, dejando de lado otros aspectos, como los mecanismos responsables por la transición de una etapa a otra, o las propuestas de políticas y acciones específicas que contribuirían a que un destino como Córdoba se sitúe en la senda del desarrollo sustentable. También sería importante diseñar y estimar indicadores adicionales, o realizar un análisis a nivel más micro, por productos o sub-regiones de la provincia. Todas éstas son líneas de trabajo interesantes, que aparecen como promisorias de cara al futuro de la investigación.

\section{BIBLIOGRAFÍA}

AGENCIA DE PROMOCIÓN DEL EMPLEO (2013): Catálogo de Formación Profesional. Córdoba, Argentina, Agencia de Promoción del Empleo, Gobierno de la Pcia. de Córdoba.

BARRIONUEVO, M.E. y PAN, M.I. (2011): «Turismo, sustentabilidad y asociatividad interorganizacional», 3er Congreso Internacional de Investigación. La Plata, Argentina, 15 al 17 de noviembre.

BLANCAS PERAL, F.J., GONZÁLES LOZANO, M., GUERRERO CASAS, F.M. y LOZANO OYOLA, M. (2010): «Indicadores sintéticos de turismo sostenible: una aplicación para los destinos turísticos de Andalucía», Rect@: Revista Electrónica de Comunicaciones y Trabajos de ASEPUMA, vol. 11, $\mathrm{n}^{\circ}$ 1, pp. 85-118. Disponible en: http://www.revistarecta.com/ (recuperado el 28/04/14). 
BUCKLEY, R. (2012): «Sustainable tourism: Research and reality», Annals of Tourism Research, vol. 39, $\mathrm{n}^{\circ} 2$, pp. 528-546.

BUTLER, R.W. (1980): «The concept of a tourist area cycle of evolution: Implications for management of resources», Canadian Geographer, vol. 24, nº 1, pp. 5-12.

BUTLER, R.W. (2011): «Tourism Area Life Cycle», Contemporary Tourism Reviews. Oxford: Goodfellow Publishers. Disponible en: http:/www.ibtcl.co.uk/web_documents/toursim_area_life_cycle_original.pdf (recuperado el 28/04/14).

CERNAT, L. y GOURDON, J. (2012): «Paths to success: Benchmarking cross-country sustainable tourism», Tourism Management, vol. 33, n 5, pp. 1044-1056.

DE GREGORI, T.R. (1987): «Resources are not; they become: An institutional theory», Journal of Economic Issues, vol. 21, no 3, pp. 1241-1263.

FORTUNY, M., SOLER, R., CÁNOVAS, C. y SÁNCHEZ, A. (2008): «Technical approach for a sustainable tourism development. Case study in the Balearic Islands», Journal of Cleaner Production, vol. 16, no 7 , pp. 860-869.

GHIMIRE, K.B. (2001): «The growth of national and regional tourism in developing countries: An overview», en K.B. Ghimire (Ed.), The Native Tourist: Mass Tourism within Developing Countries. Abingdon y New York, Earthscan, pp. 1-29.

GRIFFIN, T. (2002): «An optimistic perspective on tourism's sustainability», en R. Harris, T. Griffin y P. Williams (Eds.), op. cit., pp. 24-32.

HARRIS, R., GRIFFIN, T. y WILLIAMS, P. (2002): Sustainable Tourism: A Global Perspective. Oxford y Burlington, Butterworth-Heinemann.

HARRISON, D. (2001a): Tourism and the Less Developed World. Issues and Case Studies. Wallingford y New York, CABI Publishing.

HARRISON, D. (2001b): «Less developed countries and tourism: The overall pattern», en D. Harrison (Ed.), op. cit., pp. 1-22.

HARRISON, D. (2001c): « Tourism and less developed countries: Key issues», en D. Harrison (Ed.), op. cit., pp. 23-46.

HODGSON, G.M. (1993): «Theories of economic evolution: a preliminary taxonomy», The Manchester School, vol. 61, $\mathrm{n}^{\circ}$ 2, pp. 125-143.

HODGSON, G.M. (2004): The Evolution of Institutional Economics. London y New York, Routlegde.

HODGSON, G.M. (2007): The Evolution of Economic Institutions: A Critical Reader. Cheltenham y Northampton, Edward Elgar.

HODGSON, G.M. (2011): «Evolutionary Economics», en Encyclopedia of Life Support Systems (EOLSS). Paris, France, Eolss Publishers. Disponible en: http://www.eolss. net/sample-chapters/c04/e6-28-31.pdf (recuperado el 28/04/14).

HUNTER, C. (2002): «Aspects of the sustainable tourism debate from a natural resources perspective», en R. Harris, T. Griffin y P. Williams (Eds.), op. cit., pp. 3-23.

IERAL (2011): Una Argentina competitiva, productiva y federal. El turismo internacional en la Argentina. Documento de Trabajo, año 17, $\mathrm{n}^{\circ}$ 103. Córdoba, Argentina, IERAL de Fundación Mediterránea.

IIE (2011): Reconversión, expansión y adaptación de la oferta turística de Córdoba. Córdoba, Argentina, Instituto de Investigaciones Económicas de la Bolsa de Comercio. 
INDEC (2012): Encuesta de Ocupación Hotelera. Buenos Aires, Argentina, Instituto Nacional de Estadísticas y Censos. Disponible en: http://www.indec.gov.ar/principal. asp?id_tema=5165 (recuperado el 28/04/14).

LINDEMANS, J.W. (2012): «Methodological individualism and cultural evolution: Ontogenetic and phylogenetic approaches to social order», The Quarterly Journal of Austrian Economics, vol. 15, n 3 , pp. 331-369.

MA, M. (2013): Tourism Area Development from an Evolutionary Economic Geography Perspective. The Case of Guilin, China. Tesis doctoral. Kiel, Germany, ChristianAlbrechts-Universität zu Kiel. Disponible en: http://d-nb.info/1038694809/34 (recuperado el 28/04/14).

MINTUR (2006): Anuario Estadístico de Turismo 2006. Buenos Aires, Argentina, Secretaría de Turismo de la Nación.

MINTUR (2012): Anuario Estadístico de Turismo 2012. Buenos Aires, Argentina, Ministerio de Turismo de la Nación.

MONTAÑO ARMENDÁRIZ, A., PÉREZ CONCHA, J.C. y DE LA O BURROLA, V. (2014): «Reposicionamiento para destinos turísticos consolidados: el caso de Los Cabos, México», Cuadernos de Turismo, no 33, pp. 271-295.

MOSCARDO, G.; SCHURMANN, A.; KONOVALOV, E. y McGEHEE, N.G. (2013): «Using tourism to build social capital in communities: New pathways to sustainable tourism futures», en Conf. Proceedings of BEST EN Think Tank XIII. Kuala Lumpur, Malaysia, pp. 219-236.

OMT (2004): Indicators of Sustainable Development for Tourism Destinations A Guidebook. Madrid, España, Organización Mundial del Turismo.

OSTROM, E. y BASURTO, X. (2011): «Crafting analytical tools to study institutional change», Journal of Institutional Economics, vol. 7, n 3, pp. 317-343.

PALMER TOUS, T., CAPÓ PARRILLA, J. y RIERA FONT, A. (2007): «Tourism and natural resources: Management tools for their sustainability, en P.R. Chang (Ed.), Tourism Management in the 21st Century. New York, Nova Science Publishers, pp. 309-322.

PEETERS, P. (2012): «A clear path towards sustainable mass tourism? Rejoinder to the paper 'Organic, incremental and induced paths to sustainable mass tourism convergence' by David B. Weaver», Tourism Management, vol. 33, n 5, pp. 10381041.

PERONA, E. (2014): «In search of a new strategy for tourism development: The case of Cordoba, Argentina», 40th Annual Conference Roundtable of the East Coast Colleges Social Science Association (ECCSSA). Herndon, Virginia, USA, 4 al 5 de abril.

PERONA, E., MOLINA, E., ALLENDE GARCÍA, L., PUSSETTO, L. y FREITES, D. (2013): «Impacto económico y social del turismo en la provincia de Córdoba», Revista Oikonomos, vol. 3, n 1 , pp.59-78.

PETS (2006): Plan Estratégico de Turismo Sustentable Córdoba. Córdoba, Argentina, Agencia Córdoba Turismo. Disponible en: http://www.cordobaturismo.gov.ar/planestrategico-de-turismo-sustentable/ (recuperado el 08/05/14).

PRITCHARD, A., MORGAN, N. y ATELJEVIC, I. (2011): «Hopeful tourism: A new transformative perspective», Annals of Tourism Research, vol. 38, n 3, pp. 941-963. 
PUSSETTO, L., MOLINA, E. y PERONA, E. (2013): «Análisis de los determinantes económicos de la actividad turística en la provincia de Córdoba», $3^{\circ}$ Jornadas Nacionales y $2^{\circ}$ Internacionales de Investigación en Organización y Desarrollo Económico. San Juan, Argentina, 28 al 30 de agosto.

REN, C.; PRITCHARD, A. y MORGAN, N. (2010): «Constructing tourism research. A Critical Inquiry», Annals of Tourism Research, vol. 37, nº 4, pp. 885-904.

RICCI, M.B. (2013): Indicadores de Sustentabilidad en la Gestión del Turismo: Una radiografía en la Provincia de Córdoba-Argentina. Madrid, España, Editorial Académica Española.

ROBINSON, M. y PICARD, D. (2006): Tourism, Culture and Sustainable Development. Paris, France, UNESCO.

STURZENEGGER, A. y PORTO, N. (2008): La Importancia de la Actividad Económica de Turismo y Viajes en Argentina. Buenos Aires, Argentina, $5^{\circ}$ Informe de la Cámara Argentina de Turismo.

TAVELLA, M., MIROPOLSKY, A. y GONZÁLEZ, G. (2010): «Turismo sustentable. Fortalezas y debilidades del sector hotelero de la pcia de Córdoba», Ciencia, vol. 5, $\mathrm{n}^{\circ} 16$, pp. 131-146.

TOSUN, C. (2000): «Limits to community participation in the tourism development process in developing countries», Tourism Management, vol. 21, nº 6, pp. 613-633.

WASILCOV, T. y PERONA, E. (2014): «El sector turismo en el desarrollo de la provincia de Córdoba: resultados, logros y desafíos pendientes», Revista de Ciencia y Técnica de la Universidad Empresarial Siglo 21, vol. 7, n 2, pp. 1-16.

WEAVER, D.B. (2000): «A broad context model of destination development scenarios», Tourism Management, vol. 21, no 3, pp. 217-224.

WEAVER, D.B. (2002): «Perspectives on sustainable tourism in the South Pacific», en R. Harris, T. Griffin y P. Williams (Eds.), op. cit., pp. 121-139.

WEAVER, D.B. (2012): «Organic, incremental and induced paths to sustainable mass tourism convergence», Tourism Management, vol. 33, $\mathrm{n}^{\circ}$ 5, pp. 1030-1037.

WEAVER, D.B. y LAWTON, L. (1999): Sustainable Tourism: A Critical Analysis. Gold Coast, Queensland, Australia, CRC for Sustainable Tourism. 
